\title{
Analisis Biaya Penyakit Tuberkulosis: Studi Kasus di Salah Satu Puskesmas dan Rumah Sakit di Yogyakarta
}

\author{
Cost off iIlness of Tuberculosis: Case Study in a Primary Healthcare and \\ Hospital in Yogyakarta
}

\author{
Annisa Iswari ${ }^{1}$, Dwi Endarti ${ }^{2}$, Christiana Trijayanti ${ }^{3}$, Restu Nur Hasanah Haris ${ }^{4}$, Aulia Nadya \\ Rizki Imansari ${ }^{5}$ \\ ${ }^{1}$ Fakultas Farmasi, Universitas Gadjah Mada \\ 2 Departemen Farmasetika, Fakultas Farmasi, Universitas Gadjah Mada \\ ${ }^{3}$ RS Paru Respira Yogyakarta \\ ${ }^{4}$ Institut Teknologi dan Kesehatan Avicenna \\ ${ }^{5}$ Stikes Kharisma Persada \\ Corresponding author: Dwi Endarti: Email: endarti_apt@ugm.ac.id \\ Submitted: 11-02-2020 Revised: 31-03-2020 \\ Accepted: 15-04-2020
}

\begin{abstract}
ABSTRAK
Tuberkulosis (TB) menjadi salah satu masalah kesehatan masyarakat dunia. Saat ini angka kematian terhadap TB semakin meningkat di Indonesia. Dilaporkan kasus Tuberkulosis (TB) mencapai 420.994 kasus selama tahun 2017 dan sebanyak 8\% dari total kasus seluruh dunia di tahun 2018. Perawatan terapi yang panjang pada pasien TB menyebabkan tingginya biaya pengobatan yang harus dibayarkan oleh pasien. Studi ini bertujuan untuk melihat besarnya biaya perawatan pada pasien tuberkulosis dari perspektif societal dan faktor yang mempengaruhinya. Studi dilakukan pada pasien TB di Rumah Sakit Paru Respira Yogyakarta dan Poli Paru di Puskesmas Sewon I yang dilakukan dalam kurun waktu 3 bulan (Januari-Maret 2019). Penelitian merupakan rancangan deskriptive dengan pendekatan cross-sectional. Tehnik sampling yang digunakan adalah accidental sampling pada 35 pasien. Analisis data secara deskriptif untuk memberikan estimasi biaya dan uji beda untuk melihat faktor yang mempengaruhi biaya pasien TB. Hasil penelitian menunjukan Biaya medis langsung merupakan komponen biaya yang paling tinggi dibandingkan komponen biaya lainnya. Biaya medis langsung pasien Tuberkulosis per episode rawat jalan sebesar Rp.106.745 \pm 77.050 , non medis langsung Rp.26.024 \pm 31.247 , biaya tidak langsung sebesar Rp.70.820 \pm 71.488 . Faktor jenis pembiayaan $(\mathrm{p}=0.011)$ memberikan pengaruh signifikan terhadap biaya medis langsung. Faktor jenis kelamin $(p=0.004)$ dan status bekerja $(p=0.000)$ memberikan pengaruh signifikan terhadap biaya tidak langsung.
\end{abstract}

Kata kunci: Cost of Illness; Tuberkulosis; Societal

\section{ABSTRACT}

Tuberculosis (TB) has become one of the world's public health problems. At present the death rate for TB is increasing in Indonesia. Reported cases of tuberculosis (TB) reached 420.994 cases during 2017 and as many as 8\% of total cases worldwide in 2018. Long treatment therapy for TB patients causes high medical costs to be paid by patients. This study aims to look at the amount of care costs in tuberculosis patients from a societal perspective and the factors that influence it. The study was conducted on TB patients at the Respira Yogyakarta and Sewon Primary healthcenter conducted within a period of 3 months (January-March 2019). This Research was descriptive design with cross-sectional approach. The sampling technique used was accidental sampling in 35 patients. Descriptive data analysis to provide cost estimates and different tests to see factors influencing TB patient costs. Direct medical costs are the highest cost component compared to other cost components. Direct medical costs for Tuberculosis patients per outpatient episode were Rp.106.745 \pm 77.050 , direct non-medical Rp.26.024 \pm 31.247 , indirect costs amounted to Rp.70.820 \pm 71.488 . The type of financing factor $(\mathrm{p}=0.011)$ showed significant influence on direct medical costs. The sex $(\mathrm{p}=0.004)$ and work status $(\mathrm{p}=0.000)$ have a significant effect on indirect costs.

Keywords: Cost of Illness; Tuberculosis; Societal 


\section{PENDAHULUAN}

Penyakit TB menjadi salah satu dari 10 penyebab kematian didunia dan menjadi penyebab kematian nomor 2 pada penyakit infeksius setelah HIV (WHO, 2018 ; Sokolove dkk., 2017). Prevalensi usia penderita TB adalah usia produktif 20-60 tahun karena pada usia produktif memiliki mobilitas yang lebih tinggi sehingga akan lebih beresiko terpapar bakteri penyebab TB (Sabila, 2016).Tuberkulosis menjadi salah satu penyebab morbiditas dan mortalititas karena tingginya biaya kesehatan. Penderita TB membutuhkan pengobatan yang lama untuk sembuh, mencegah kematian, mencegah kekambuhan dan menurunkan tingkat penularan sehingga membutuhkan biaya yang tinggi (Depkes, 2017). Pengobatan TB merupakan program pemerintah yang menyediakan obat gratis dalam sistem Directly Observed Treatment Shortcourse (DOTS), namun pengobatan TB masih melibatkan biaya tinggi yang mendorong orang dalam kemiskinan (Saqib dkk., 2018). Tuberkulosis tidak hanya mempengaruhi biaya medis langsung, namun juga mempengaruhi biaya tidak langsung yang akan memberikan beban kepada penderita TB dan keluarga pasien yang menemani dalam hal kehilangan produktivitas dan hilangnya pendapatan akibat ketidakhadiran bekerja. Hilangnya produktivitas kematian dini menjadi elemen terbesar dari beban biaya TB (Collins dkk., 2017). Studi ini bertujuan untuk melihat biaya perawatan pada pasien tuberkulosis dan melihat faktor yang mempengaruhi. Analisis biaya penyakit tuberkulosis menjadi penting karena dapat mengevaluasi beban ekonomi dari penyakit TB yang dapat memberikan masukan bagi pemerintah tentang biaya pengobatan pasien TB meliputi biaya langsung dan biaya tidak langsung.

\section{METODOLOGI}

Penelitian ini menggunakan rancangan penelitian deskriptif dengan pendekatan crosssectional. Lokasi pengambilan sampel bertempat di Rumah Sakit Paru Respira Yogyakarta dan Poli Paru Puskesmas Sewon I. Penelitian ini mendapatkan persetujuan etik dari Komisi Etik Fakultas Kedokteran UGM Nomor: KE/FK/1019/EC tanggal 24 September 2018. Teknik sampling yang digunakan adalah accidental sampling pada 35 pasien. Perspektif yang digunakan dalam menganalisis biaya perawatan pasien TB adalah perspektif societal.
Pasien dengan diagnosa utama tuberkulosis umur $>18$ tahun, memiliki data pembiayaan lengkap dan bersedia menjadi responden dalam penelitian ini merupakan kriteria inklusi sedangkan pasien dengan komplikasi berat (HIV-DM), pasien meninggal ataupun pindah ke RS lain adalah kirteria eksklusi. Data yang digunakan diambil secara retrospektif, untuk biaya medis langsung dikumpulkan dari data pembiayaan pasien yang memenuhi kriteria inklusi dan eksklusi. Biaya non medis langsung dan biaya tidak langsung diambil secara concurrent yang dilakukan dengan wawancara langsung kepada pasien. Data dianalisis secara deskriptif untuk memberikan estimasi biaya perawatan pasien, uji Mann-Whitney dan Kruskall-Wallis digunakan untuk melihat faktor yang mempengaruhi biaya perawatan pada pasien Tuberkulosis di RS Paru Respira Yogyakarta dan Puskesmas Sewon I. Faktor usia dan jenis pembiayaan dianalisis hubungannya dengan biaya medis langsung karena variabel usia diduga berhubungan dengan terapi yang diberikan sehingga mempengaruhi biaya medik langsung, demikian juga jenis pembiayaan diduga mempengaruhi tarif pelayanan yang berbeda sehingga mempengaruhi biaya medis langsung. Faktor jenis kelamin dan status bekerja dianalisis hubungannya dengan biaya tak langsung karena variabel tersebut diduga mempengaruhi produktivitas yang hilang karena sakit dan perawatan.

\section{HASIL DAN PEMBAHASAN}

Karakteristik Pasien Tuberkulosis (TB) dengan perspektif societal

Karakteristik pasien dalam studi ini menunjukan bahwa pasien tuberkulosis lebih banyak diderita oleh laki-laki (45,7\%) dibandingkan perempuan. Dalam penelitian di Afrika Selatan dikatakan bahwa laki-laki lebih beresiko terkena penyakit tuberkulosis dibandingkan perempuan (Leslie dkk., 2014). Aktifitas yang lebih padat diluar rumah dan kebiasaan merokok oleh laki-laki dapat menjadi pemicu. Dilansir oleh WHO rasio terjadinya penyakit TB pada laki-laki dan perempuan 2:1 (WHO, 2018). Sebanyak 48,6\% pasien berumur 45-64 tahun. 45,7\% pasien TB masih bekerja, yang artinya walaupun telah didiagnosa TB pasien tidak merasa terganggu dalam kegiatan sehari-hari dan rutinitas bekerja. Dari hasil wawancara $48,6 \%$ pasien memiliki riwayat merokok kemudian berhenti setelah didiagnosa 
Tabel I. Karakteristik semua pasien tuberkulosis di RS Paru Respira Yogyakarta dan Puskesmas Sewon I $(\mathrm{N}=35)$

\begin{tabular}{|c|c|c|c|c|}
\hline \multirow[b]{2}{*}{$\begin{array}{c}\text { Karakteristik } \\
\text { Pasien }\end{array}$} & \multicolumn{3}{|c|}{ Jumlah Pasien } & \multirow[b]{2}{*}{$\begin{array}{c}\text { Persentase } \\
(\%)\end{array}$} \\
\hline & $\begin{array}{c}\text { RS.Paru Respira } \\
\text { Yogyakarta }(n=25)\end{array}$ & $\begin{array}{c}\text { Puskesmas Sewon I } \\
(\mathrm{n}=10)\end{array}$ & $\begin{array}{c}\text { Total } \\
(n=35)\end{array}$ & \\
\hline \multicolumn{5}{|l|}{ Jenis Kelamin } \\
\hline Laki-laki & 13 & 3 & 19 & 54,3 \\
\hline Perempuan & 12 & 7 & 16 & 45,7 \\
\hline \multicolumn{5}{|l|}{ Usia } \\
\hline $18-24$ & 4 & 2 & 6 & 17,1 \\
\hline $25-44$ & 9 & 1 & 10 & 28,6 \\
\hline $45-64$ & 12 & 5 & 17 & 48,6 \\
\hline$>65$ & 0 & 2 & 2 & 5,7 \\
\hline \multicolumn{5}{|l|}{ Status Bekerja } \\
\hline Bekerja & 11 & 5 & 16 & 45,7 \\
\hline Tidak bekerja & 5 & 3 & 8 & 22,9 \\
\hline Pensiunan & 9 & 2 & 11 & 31,4 \\
\hline \multicolumn{5}{|l|}{ Riwayat Merokok } \\
\hline Tidak pernah & 13 & 3 & 16 & 45,7 \\
\hline Masih merokok & 1 & 1 & 2 & 5,7 \\
\hline Berhenti & 11 & 6 & 17 & 48,6 \\
\hline \multicolumn{5}{|l|}{ Jenis Pembiayaan } \\
\hline Umum & 6 & 0 & 6 & 17,15 \\
\hline BPJS & 19 & 10 & 29 & 82,85 \\
\hline \multicolumn{5}{|l|}{ Pekerjaan } \\
\hline Wiraswasta & 13 & 1 & 14 & 40,0 \\
\hline Petani & 3 & 2 & 5 & 14,3 \\
\hline IRT & 3 & 2 & 5 & 14,3 \\
\hline Buruh & 4 & 3 & 7 & 20,0 \\
\hline PNS & 1 & 1 & 2 & 5,7 \\
\hline Mahasiswa & 0 & 1 & 1 & 2,9 \\
\hline Tidak bekerja & 1 & 0 & 1 & 2,9 \\
\hline
\end{tabular}

TB, 45,7\% dilaporkan merupakan perokok pasif. Menurut penelitian Silva dkk. faktor pemicu terjadinya tuberkulosis bukan hanya karena memiliki riwayat merokok tetapi juga dikarenakan adanya penyakit lain (DM, HIV) serta kebiasaan mengkonsumis alkohol (Silva dkk., 2018). Sebanyak 40\% pasien merupakan wiraswasta dan sebagian besar pembiayaan perawatan pasien ditanggung oleh BPJS $(82,85 \%)$. Karakteristik semua pasien tuberkulosis di RS.Paru Respira Yogyakarta dan Puskesmas Sewon I dapat dilihat pada tabel I. Tabel I juga menunjukkan proporsi jumlah pasien baik pada RS.Paru Respira Yogyakarta dan Puskesmas Sewon I, terlihat bahwa jumlah pasien lebih banyak pada Rumah Sakit dibandingkan pada Puskesmas. Dari 117 populasi didapatkan total 35 subyek penelitian yang terdiri dari 25 subyek pasien di RS Paru
Respira Yogyakarta dan 10 subyek pasien di Puskesmas Sewon I serta terdapat 290 total kasus rawat jalan yang terdiri dari 202 kasus di Rumah Sakit dan 88 kasus rawat jalan di Puskesmas yang dilakukan pasien selama periode Juli 2018 - Maret 2019.

\section{Analisis Biaya pasien Tuberkulosis (TB)}

Analisis biaya yang digunakan ditinjau dari perspektif societal yang mana semua biaya diperhitungkan, baik biaya medis langsung, biaya non medis langsung dan biaya tidak langsung. Tabel II menunjukan bahwa biaya obat dan barang medis $(54,27 \%)$ merupakan biaya yang paling tinggi (Rp.57.932 \pm 73.481 ) dibandingkan biaya lainnya dalam komponen biaya medis langsung pada pasien TB. Hasil ini sejalan dengan penelitian Sari dkk. dikatakan bahwa sebesar $55,21 \%$ biaya obat dan barang 
Tabel II. Total dan perbandingan komponen biaya rawat jalan TB di RS Paru Respira Yogyakarta dan Puskesmas Sewon I per episode rawat jalan berdasarkan perspektif societal $(\mathrm{n}=290$ kunjungan).

\begin{tabular}{|c|c|c|c|c|c|c|c|}
\hline Komponen Biaya & $\begin{array}{c}\text { Rata- } \\
\text { rata } \\
\text { (Rp) }\end{array}$ & $\begin{array}{l}\text { Median } \\
\text { (Rp) }\end{array}$ & $\begin{array}{l}\text { Max } \\
\text { (Rp) }\end{array}$ & $\begin{array}{l}\text { Min } \\
\text { (Rp) }\end{array}$ & $\begin{array}{l}\text { SD } \\
\text { (Rp) }\end{array}$ & $\begin{array}{c}\text { SE } \\
\text { (Rp) }\end{array}$ & $\begin{array}{c}\text { Persentase } \\
(\%)\end{array}$ \\
\hline \multirow{2}{*}{\multicolumn{8}{|c|}{ Biaya Medis }} \\
\hline & & & & & & & \\
\hline Adminstrasi & 6.034 & 6.000 & 9.000 & 5.500 & 797 & 46 & 5,65 \\
\hline $\begin{array}{l}\text { Obat\&Barang } \\
\text { Medis }\end{array}$ & 57.932 & 46.573 & 523.105 & 0 & 73.481 & 4.314 & 54,27 \\
\hline $\begin{array}{l}\text { Jasa Pelayanan } \\
\text { Medis }\end{array}$ & 23.405 & 27.500 & 27.500 & 15.000 & 5.876 & 345 & 21,92 \\
\hline Penunjang Medis & 19.373 & 0 & 100.000 & 0 & 31.605 & 1.855 & 18,14 \\
\hline Total & $\begin{array}{c}106.74 \\
5\end{array}$ & 81.999 & 556.605 & 24.490 & 77.050 & 4.524 & 100 \\
\hline \multicolumn{8}{|l|}{$\begin{array}{l}\text { Biaya Non Medis } \\
\text { Langsung }\end{array}$} \\
\hline $\begin{array}{l}\text { Transportasi } \\
\text { pasien }\end{array}$ & 10.217 & 5.000 & 50.000 & 0 & 10.475 & 615 & 39,24 \\
\hline Makan pasien & 4.837 & 0 & 50.000 & 0 & 7.857 & 461 & 18,58 \\
\hline $\begin{array}{l}\text { Transportasi } \\
\text { Keluarga }\end{array}$ & 7.679 & 4.000 & 50.000 & 0 & 13.264 & 778 & 29,50 \\
\hline Makan Keluarga & 3.289 & 0 & 50.000 & 0 & 7.528 & 442 & 12,63 \\
\hline $\begin{array}{l}\text { Total } \\
\text { Biaya Tidak } \\
\text { Langsung } \\
\text { Riil }\end{array}$ & 26.024 & 20.000 & 200.000 & 0 & 31.247 & 1.834 & 100 \\
\hline $\begin{array}{l}\text { Produktivitas } \\
\text { Pasien }\end{array}$ & 58.479 & 45.000 & 318.000 & 0 & 62.118 & 3.647 & 82,57 \\
\hline $\begin{array}{l}\text { Produtikvitas } \\
\text { Keluarga }\end{array}$ & 12.341 & 0 & 181.000 & 0 & 23.660 & 1.389 & 17,43 \\
\hline $\begin{array}{l}\text { Total } \\
\text { Biaya Tidak } \\
\text { Langsung } \\
\text { Estimasi }\end{array}$ & 70.820 & 59.000 & 499.000 & 0 & 71.488 & 4.197 & 100 \\
\hline $\begin{array}{l}\text { Produktivitas } \\
\text { Pasien }\end{array}$ & $\begin{array}{c}153.97 \\
8\end{array}$ & 153.978 & 153.978 & 153.978 & 0 & 0 & 71,25 \\
\hline $\begin{array}{l}\text { Produktivitas } \\
\text { Keluarga }\end{array}$ & 62.122 & 0 & 153.978 & 0 & 75.670 & 4.443 & 28,75 \\
\hline Total & $\begin{array}{c}216.10 \\
0\end{array}$ & 153.978 & 307.956 & 153.978 & 75.670 & 4.443 & 100 \\
\hline
\end{tabular}

medis menjadi komponen biaya yang paling besar dibandingkan dengan total biaya medis langsung selama 6 bulan perawatan (Sari dkk., 2017). Dari hasil penelitian ditemukan bahwa biaya transportasi pasien dan keluarga selama perawatan memberikan biaya yang cukup tinggi $(39,24 \%)(29,50 \%)$ dalam komponen biaya non medis langsung dengan biaya per-episode Rp.10.217 \pm 10.475 dan Rp.7.679 \pm 13.264 . Hal ini dikarenakan pasien dan keluarga harus bolakbalik ke Rumah Sakit dan Puskesmas untuk melakukan perawatan dengan jarak yang cukup jauh, sedangkan biaya makan untuk keluarga menjadi komponen biaya yang paling rendah $(12,63 \%)$ dikarenakan keluarga tidak mengeluarkan banyak uang untuk makan selama perawatan. Dalam komponen biaya tidak langsung, hilangnya produktivitas pasien 
Tabel III. Rekapitulasi biaya pasien TB per episode rawat jalan di RS Paru Respira Yogyakarta dan Puskesmas Sewon I berdasarkan perspektif societal ( $\mathrm{n}=290$ kunjungan)

\begin{tabular}{lcccc}
\hline Komponen Biaya & Jumlah (Rp) & Rata-rata (Rp) & SD (Rp) & Persentase (\%) \\
\hline Biaya Medis Langsung & 30.956 .248 & 106.745 & 77.050 & 52,43 \\
Biaya Non Medis Langsung & 7.547 .000 & 26.024 & 31.247 & 12,78 \\
Biaya Tidak Langsung & 20.537 .900 & 70.820 & 71.488 & 34,57 \\
Rill & & & & \\
TOTAL & $\mathbf{5 9 . 0 4 1 . 1 4 8}$ & $\mathbf{2 0 4 . 8 3 1}$ & $\mathbf{1 2 8 . 0 9 2}$ & $\mathbf{1 0 0}$ \\
Biaya Medis Langsung & 30.956 .248 & 106.745 & 77.050 & 30,59 \\
Biaya Non Medis Langsung & 7.547 .000 & 26.024 & 31.247 & 7,45 \\
Biaya Tidak Langsung & 62.669 .046 & 216.100 & 75.670 & 61,94 \\
Estimasi & & & & \\
TOTAL & $\mathbf{1 0 1 . 1 7 2 . 2 9 4}$ & $\mathbf{3 5 0 . 1 1 1}$ & $\mathbf{1 2 8 . 4 5 3}$ & $\mathbf{1 0 0}$ \\
\hline
\end{tabular}

biasanya menjadi biaya yang paling besar. Dalam penelitian ini hilangnya produktivitas pasien dihitung dengan pendekatan rill dan pendekatan estimasi. Pendekatan riil dihitung berdasarkan besarnya penghasilan riil pasien yang biasanya diterima, sedangkan pendekatan estimasi dihitung berdasarkan nilai produk domestik bruto /PDB per kapita (gross domestic product/GDP per capita). Hasil yang didapatkan hilangnya produktivitas pasien dengan pendekatan estimasi (Rp.153.978 \pm ) lebih tinggi dibandingkan dengan biaya rill (Rp.58.478 \pm 62.188 ) yang dikeluarkan oleh pasien. Hal ini disebabkan karena sebelumnya, peneliti tidak mempertimbangkan pasien bekerja atau tidak tetapi langsung diasumsikan bahwa pasien mempunyai penghasilan Rp.153.978 per-hari (berdasarkan perhitungan biaya tenaga kerja tahunan di Indonesia dan jumlah hari). Total dan perbandingan komponen biaya rawat jalan TB di RS Paru Respira Yogyakarta dan Puskesmas Sewon I dapat dilihat pada Tabel II.

Tabel III menunjukan bahwa biaya medis langsung menjadi komponen biaya yang paling tinggi dalam biaya perawatan pasien tuberkulosis di RS.Paru Respira Yogyakarta dan Puskesmas Sewon I (52,43\%). Hal ini sejalan dengan penelitian Hosoumi dkk. yang menyatakan bahwa direct medical cost adalah proporsi biaya terbesar dalam perawatan pasien TB (Hosoumi dkk., 2011). Tingginya biaya medis langsung juga sejalan dengan penelitian Gurung dkk. yang mencatat bahwa biaya medis langsung menghabiskan lebih dari $50 \%$ dari total pembiayaan, hal ini jauh lebih besar dibandingkan komponen biaya yang lain (Gurung dkk., 2012). Rekapitulasi biaya pasien
TB di RS Paru Respira Yogyakarta dan Puskesmas Sewon I dapat dilihat pada Tabel III.

Analisis Pengaruh Faktor Usia dan Jenis Pembiayaan terhadap biaya medis langsung pasien TB.

Dari uji Mann-Whitney, didapatkan hasil bahwa besarnya biaya perawatan pada pasien TB berpengaruh pada jenis pembiayaan di Rumah Sakit maupun Puskesmas $(\mathrm{p}=0.011)$. Adanya perbedaan rata-rata biaya obat dan barang medis baik itu di Rumah Sakit dan puskesmas disinyalir menjadi penyebabnya. Pasien TB yang menjalani perawatan rutin di Puskesmas Sewon I hanya mendapatkan obat jenis TBC-FDC walaupun pasien memiliki keluhan penyakit lain. Sedangkan pasien yang menjalani perawatan TB di RS.Paru Respira Yogyakarta bila memiliki keluhan lain selain TBC petugas farmasi akan memberikan obat lain untuk simptomatik pasien. Adanya penambahan komponen obat tersebut membuat biaya obat yang semakin tinggi. Faktor usia tidak memberikan pengaruh terhadap biaya perawatan pasien TB $(p=0.407)$. Karakteristik pasien TB terhadap biaya medis langsung dapat dilihat pada Tabel IV.

Analisis Pengaruh Faktor Jenis Kelamin dan
status bekerja terhadap biaya tidak
langsung pasien TB.
Faktor jenis kelamin memberikan
pengaruh terhadap biaya tidak langsung pada
pembiayaan perawatan pasien TB ( $\mathrm{p}=0.004)$.
Hilangnya produktifitas pada pasien TB akan
berpengaruh pada pendapatan pasien, terutama
apabila pasien adalah seorang laki-laki yang
menjadi kepala keluarga. Hasil ini sejalan 
Tabel IV. Karakteristik pasien TB rawat jalan terhadap biaya medis langsung di RS Paru Respira Yogyakarta dan Puskesmas Sewon I ( $\mathrm{n}=290$ kunjungan).

\begin{tabular}{|c|c|c|c|c|c|}
\hline $\begin{array}{l}\text { Karakteristik } \\
\text { Pasien }\end{array}$ & $\begin{array}{l}\text { Jumlah } \\
\text { Pasien }\end{array}$ & $\begin{array}{c}\text { Total } \\
\text { Biaya (Rp) } \\
\end{array}$ & $\begin{array}{c}\text { Rata-rata } \\
\text { (Rp) }\end{array}$ & $\begin{array}{l}\text { SD } \\
\text { (Rp) }\end{array}$ & $\boldsymbol{P}$ \\
\hline \multicolumn{6}{|l|}{ Usia } \\
\hline $18-24$ & 6 & 748.890 & 124.815 & 65.324 & \multirow{4}{*}{0,407} \\
\hline $25-44$ & 10 & 1.208 .161 & 120.816 & 48.113 & \\
\hline $45-66$ & 17 & 1.991 .878 & 117.169 & 77.954 & \\
\hline$>65$ & 2 & 147.050 & 73.525 & 985 & \\
\hline \multicolumn{6}{|c|}{ Jenis Pembiayaan semua pasien } \\
\hline Umum & 6 & 898.228 & 149.074 & 42.237 & \\
\hline BPJS & 29 & 2.996 .683 & 103.333 & 68.002 & $0,011^{*}$ \\
\hline \multicolumn{6}{|c|}{ Jenis Pembiayaan pasien RS Paru Respira Yogyakarta } \\
\hline Umum & 6 & 898.228 & 149.074 & 42.237 & \\
\hline BPJS & 19 & 2.250 .520 & 118.448 & 80.523 & 0,092 \\
\hline
\end{tabular}

Tabel V. Karakteristik pasien TB rawat jalan terhadap biaya tidak langsung pasien di RS Paru Respira Yogyakarta dan Puskesmas Sewon I

\begin{tabular}{llllll}
\hline $\begin{array}{l}\text { Karakteristik } \\
\text { Pasien }\end{array}$ & $\begin{array}{l}\text { Jumlah } \\
\text { Pasien }\end{array}$ & $\begin{array}{c}\text { Total Biaya } \\
\text { (Rp) }\end{array}$ & $\begin{array}{c}\text { Rata-rata } \\
\text { (Rp) }\end{array}$ & $\begin{array}{c}\text { SD } \\
\text { (Rp) }\end{array}$ & P \\
\hline Jenis Kelamin & & & & & \\
Laki-laki & 19 & 1.564 .400 & 82.336 & 75.235 & $0,004^{*}$ \\
$\begin{array}{l}\text { Perempuan } \\
\text { Status Bekerja }\end{array}$ & 16 & 513.000 & 32.062 & 53.427 & \\
$\begin{array}{l}\text { Bekerja } \\
\text { Tidak bekerja }\end{array}$ & 16 & 1.310 .700 & 81.918 & 78.785 & \\
Pensiun & 8 & 0 & 0 & 0 & $0,000^{*}$ \\
\hline
\end{tabular}

dengan penelitian Anathakrisman dkk. di India Selatan yang menunjukan bahwa terdapat perbedaan yang signifikan terhadap biaya tidak langsung pada pasien TB laki-laki dan perempuan, dimana pasien laki-laki menunjukan proporsi biaya yang lebih besar (Anathakrisman dkk., 2012). Perbedaan yang signifikan juga terjadi pada penelitian Umar dkk. di Nigeria, total pendapatan yang hilang karena perawatan TB akan berpengaruh terhadap biaya tidak langsung dengan proporsi biaya pasien TB laki-laki lebih tinggi $(\$ 960,65)$ dibandingkan pada pasien TB perempuan $(\$ 449,90)$ (Umar dkk., 2012). Selain faktor jenis kelamin status dalam bekerja juga turut mempengaruhi $(p=0.000)$. Apabila pasien bekerja dan memiliki penghasilan maka biaya tidak langsung akan semakin meningkat, berbeda hal bila pasien yang sudah tidak bekerja/pensiun. Dalam penelitian Anathakrisman dkk. biaya tidak langsung pasien dengan status bekerja (Rs.3945) akan lebih besar dibandingkan pasien dengan status tidak bekerja (Rs.2014) (Anathakrisman dkk., 2012), begitupula pada penelitian Fuady dkk. yang mendukung hasil penelitian ini dikatakan bahwa pasien yang kehilangan pekerjaan setelah di diagnosa TB akan kehilangan penghasilan sehingga menjadi pendorong utama meningkatnya beban total biaya pasien (Fuady dkk., 2018). Karakteristik pasien TB terhadap biaya tidak langsung dapat dilihat pada Tabel V.

\section{KESIMPULAN}

Biaya medis langsung pasien TB per kunjungan rawat jalan adalah Rp. $106.745 \pm$ 77.050, biaya non medis langsung Rp. $26.024 \pm$ 31.247, biaya tidak langsung Rp. $70.820 \pm$ 71.488 dan total biaya Rp. $204.831 \pm 128.092$. Faktor jenis pembiayaan berpengaruh signifikan terhadap biaya medis langsung pasien TB $(p=0.011)$ dan Faktor jenis kelamin $(p=0.004)$ dan status bekerja $(p=0.000)$ berpengaruh signifikan terhadap biaya tidak langsung pasien TB. 


\section{UCAPAN TERIMA KASIH}

Penelitian ini merupakan bagian dari penelitian skripsi Annisa Iswari pada Fakultas Farmasi Universitas Gadjah Mada.

\section{DAFTAR PUSTAKA}

Anantakhrisnan, R., Muniyandi, M., Jeyaraj, A., Palani, G., Sathiyasekaran, B.W.C., 2012, Expenditure Pattern for TB Treatment among Patients Registered in an Urban Government DOTS Programin Chennai City, South India, Tuberculosis Research and Treatment, 2012: 1 - 6 .

Collins, D., Hafidz, F., Mustikawati, D. 2017, The Economic Burden of Tuberculosis in Indonesia, Management Sciences for Health, Medford, Massachusetts, USA; Universitas Gadjah M ada, Yogyakarta, Ministry of Health, Jakarta, Indonesia, International Journal Tuberculosis Lung Disease 21(9):1041-1048.

Departemen Kesehatan RI., 2017, Pengobatan Pasien Tuberkulosis, Kementerian Kesehatan RI. Direktorat Jendral Pencegahan dan Pengendalian Penyakit, Jakarta.

Fuady, A., Houweling, T.A.J., Mansyur, M., Richardus, J.H., 2018, Catastropic total cost in tuberculosis- affected households and their determinants since Indonesia's implementation of universal health coverage. Infectious of Disease Poverty, $7: 3$

Gurung, G.N., Chhetri, P.S., Jha, N., 2012, Economic Impact of Pulmonary Tuberculosis on Pateint and their families of Dharan Municipality Nepal. Nepal Med Coll J, 14(3): 196-198.

Hasoumi, M., Nasehi, M., Khakian, M., Mohseni, M., Ziaiifar, H., Keykale, M.S. 2014, Cost of
Illness of Tuberculosis in Tehran in the Year 2011, Mater Sociomed, 26(5) : 339342.

Leslie, Alasdair., Nhamoyebonde., Shepherd., 2014, Biological Difference Between the Sexes and Susceptibility to Tuberculosis, The Journal of Infectious Diseases, 209 ( Suppl 3):100-106.

Sabila, D., 2016, Analisis Biaya Pengobatan Berdasarkan Clinical Pathway Tuberkulosis Paru di RSUD Sultan Syarif Mohamad Alkadrie kota Pontianak, Skripsi, Fakultas Kedokteran Universitas Tanjung Pura, Pontianak.

Saqib, S.E., Ahmad, M.M., Prieto, C.A., 2018, Economic burden of tuberculosis and its coping mechanismat the household level in Pakistan, The Social Science Journal, 55: 313-322.

Sari, I.D., Herman, M.J., Susyanty, A.L., Su'ud, A., 2017, Analisis Biaya Tuberkulosis Paru Kategori Satu Pasien Dewasa di Rumah Sakit di DKI Jakarta, Jurnal Kefarmasian Indonesia, 8 (1): 44-54.

Silva, D.R., Torrico, M.M., et al.,2018, Risk Factor Tuberculosis: Diabetes Mellitus, Smoking, Alcohol use, and the use of the other drugs, Jornal Brasileiro de Pneumologia, 44(2): 145-152.

Sokolove, P.E. dan Derlet, R.W., 2017, Concept and Clinical Practice, , Rosen's Emergency Medicine Book, 9th edition, Tuberculosis Chapter 127, California.

Umar, N.A., Fordham, R., Abubakar, I., Bachman, M., 2012 The indirect cost due to pulmonary Tuberculosis in patients receiving treatment in Bauchi StateNigeria, Cost Effectiveness and Resource Allocation, 10:6.

WHO, 2018, Global Tuberculosis Report, WHO, Geneva 